\title{
Experimental Investigation, Modelling and Comparison of Kerfwidth in Laser Cutting of GFRP
}

\author{
Pathik Patel, Bhavin S. Modi, Saurin Sheth and Tejas Patel
}

\begin{abstract}
Day by day use of composite materials increases due to their superior strength to weight ratio and stiffness to weight ratio at high service temperatures. Aeronautic, aerospace, automotive and marine industry are the dominant consumers of the composites, but their properties like brittleness, anisotropy and non-homogeneity make it a difficult to machine by conventional machining methods. This leads to study the machinability characteristics of composites. Laser machining offers an attractive machinability as an alternative for machining the composites. The present investigation deals with the laser machining of the Glass Fibre Reinforced Plastic (GFRP) Composite. Experiments were performed based on Taguchi $L_{27}$ orthogonal array in order to investigate the effect of laser cutting parameters: Laser Power, Cutting Speed and Gas Pressure on cut quality parameter Kerfwidth. Based on the experimental results, Second Order Regression, Artificial Neural Network (ANN) and Fuzzy Logic (FL) based predictive models have been developed. Then an attempt is made to compare the results of statistical technique with computational technique. After comparing the experimental results and the predicted results it is found that the data for each response are well fitted in the developed models and these models can be used for predicting the kerfwidth within the specific range of inputs for a given machine tool with more than $95 \%$ accuracy.
\end{abstract}

Keywords--- Artificial Neural Network, Composite Materials, Fuzzy Logic, Laser Machining, Machinability, Regression

\section{INTRODUCTION}

$\mathrm{C}$ OMPOSITE materials are highly promising materials for applications in the aeronautic, aerospace, automotive and marine industry [1], [3]. These composites have advantages over other materials due to their superior strength to weight and stiffness to weight ratios at high service temperatures.

Pathik Patel, Assistant Professor, Mechatronics Department, G. H. Patel College of Engineering \& Technology, V. V. Nagar, Gujarat, India. E-mail: pathikpatel@gcet.ac.in

Bhavin S. Modi, Assistant Professor, Mechanical Engineering Department, B. V. M. Engineering College,V. V. Nagar, Gujarat,IndiaE-mail: bhavinmodi503@gmail.com

Saurin Sheth, Associate Professor, Mechatronics Department, G. H. Patel College of Engineering \& Technology, V. V. Nagar, Gujarat, India. E-mail: saurinsheth@gcet.ac.in

Tejas Patel, Assistant Professor, Mechatronics Department, G. H. Patel College of Engineering \& Technology, V. V. Nagar, Gujarat, India. E-mail: tejaspatel@gcet.ac.in

DOI: 10.9756/BIJIEMS.8052
Glass Fibre Reinforced Plastic Composites or GFRP are unique composite material consisting of glass fibres embedded in an epoxy or polyester matrix. Their low density, good thermal stability and excellent mechanical properties at elevated temperatures make them an ideal material for aircraft and aerospace, automotive, marine and marine accessories, constructions, electrical components and corrosion resistant products. It can withstand high temperature without much deformation.

\section{MACHINING OF COMPOSITES AND LiMITATIONS}

Glass fibre reinforced composites have densities in the range of 1.6-2.6 gm/ $/ \mathrm{cm}^{3}$, much lower than those of metals and ceramics and hence make lower component weight an important consideration for aero-vehicles. However, they are anisotropic and non-homogeneous in nature, and their intrinsic brittleness and hardness make machining difficult [1], [4]. Some researchers have established the feasibility of applying conventional machining techniques to machine composites. According to their results, conventional methods damage the workpiece through chipping, cracking, delamination and high wear on the cutting tools [1], [4]. Therefore, other researchers have established that polymer matrix composites can be machined easily using nontraditional machining methods especially with laser machining due to improved end product quality, low cost and short processing time. Laser Machining offers an attractive alternative method because it is a noncontact, abrasion less technique eliminates tool wear, machine-tool deflections, vibrations and cutting forces, moreover it can be used for almost all type of materials. Patel et. al.,[1] have studied a review on composites and laser machining of composites in terms of scope, limitation and application. Caprino et. al., [5] have studied cutting glass fibre reinforced plastic (GFRP) composites using a $\mathrm{CO}_{2}$ laser with Multimodal-Gaussian power distribution and proposed an analytical model which allows the depth of the kerf to be predicted. Methew et. al.,[6] have studied laser cutting of CFRP and the effect of process parameters viz. cutting speed, pulse energy, pulse duration, pulse repetition rate and gas pressure on HAZ, kerfwidth and taper angle. They have establish various relations between input and output parameters. Cenna et. al.,[7] have developed a theoretical model by performing laser cutting experiments on AFRP and GFRP samples. The developed model predicts the kerfwidth at entry and exit, material removal rate and energy transmitted through the kerf. Sulaiman et. al.,[8]have studied laser cutting of the plain-weave carbon/carbon fibers and the effect of laser power on kerfwidth and the size of striation formation. The 
result shows that with increase in laser power the kerfwidth increases. Dubey et. al.,[9] have discussed a hybrid Taguchi method and response surface method (TMRSM) approach to develop the response models and to optimize kerfwidth and material removal rate. Their result shows improvement in quality characteristics when the hybrid approach is used, as compared to the results of a single approach. Karazi et. al.,[10] have developed and compare ANN and DOE model for prediction of laser machined micro-channel dimensions. They found ANN model showed an improved predictive capability that was approximately twice as good as that provided from the DOE model. Tsai et. al.,[11] have developed multiple regression and ANN model to predict cutting qualities in diode pumped solid state laser. Sheth et. al.,[12] have experimentally investigate and compare various modeling techniques for prediction of weld width in MIG welding for dual plate check valve. Parandoush et. al.,[13] have reviewed various method for modelling and simulation of laser beam machining process and research carried so far in this area. Patel et. al.,[14] studied the effect of MIG welding process parameter on weld height. They have developed ANN and regression models to predict weld height in context of input parameters and compared with experimental data. Sivarao et. al., [17] has develop Fuzzy based Graphical User Interface (GUI) for modeling of laser machining conditions in terms of surface roughness using MATLAB toolbox. The models were then compared for their statistical validation by Root Mean Square Error (RMSE). Pandey et. al., [18]have studied a hybrid approach of Artificial Neural Network (ANN), Fuzzy Logic (FL) and Adaptive Neuro Fuzzy Inference System (ANFIS) for developing the kerfwidth and Material Removal Rate (MRR) models and found that ANFIS model is better compare to other two models.Sheth et. al., [19], [20] have studied the performance of the flashing machine for steel ball manufacturing. They have performed DOE and analyzed experimentally the influence of the groove depth of plates on MRR. Also they have developed a fuzzy model to predict the response.

The present study consists of effect of process parameters on kerfwidth in laser cutting of glass fibre reinforced plastic composites. The various input parameters viz. laser power $(\mathrm{P})$, cutting speed $(\mathrm{V})$ and gas pressure $(\mathrm{p})$ were taken under experimental investigation and then predictive models have been developed. Experiments were performed based on Taguchi $\mathrm{L}_{27}$ orthogonal array then Regression, ANN and Fuzzy Logic models have been developed to predict kerfwidth in context of cutting parameters. Moreover statistical analysis has been done to find the closeness of the predicted values with the experimental data.

\section{EXPERIMENTAL PROCEDURE}

\section{A. Material Preparation}

A $5 \mathrm{~mm}$ thick sheet of glass fibre reinforced plastic composite is used for experiments. In this composite material, fibres were made of E-glass in chopped form and the matrix material was polyester resin. The test specimen is shown in figure 1, [2].

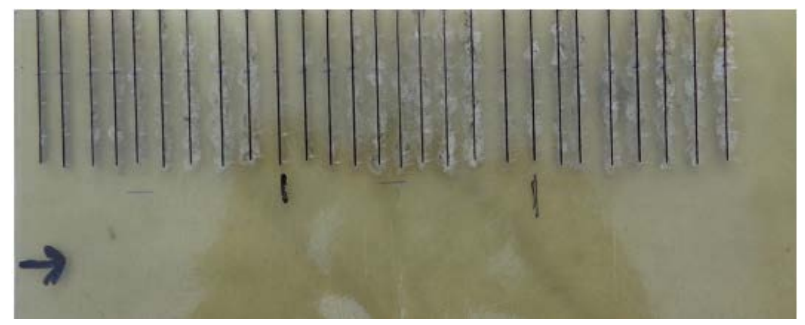

Figure 1: Experimental Specimen

\section{B. Experimental Setup}

All experiments were conducted using a fibre laser cutting machine (Sahajanand Laser Technology Limited, Gandhinagar) with CNC work table which is capable of giving a maximum output power of $2000 \mathrm{~W}$ in continuous mode. The independent and fixed input parameters and there levels were decided based on the literature and by performing number of trial experiments. Nitrogen gas was used as an assist gas at right angle and coaxially to the laser beam. The laser beam was focused using a lens of $125 \mathrm{~mm}$ focal length, the nozzle diameter was $1.5 \mathrm{~mm}$ and the nozzle tip distance was $1.5 \mathrm{~mm}$. The levels selected are summarized in table 1, [2].

Table 1: Input Parameter Values

\begin{tabular}{|c|c|c|c|c|}
\hline Parameters & Units & Level 1 & Level 2 & Level 3 \\
\hline Laser Power & Watt & 1200 & 1300 & 1400 \\
\hline Cutting Speed & $\mathrm{mm} / \mathrm{min}$ & 400 & 500 & 600 \\
\hline Gas Pressure & Bar & 14 & 16 & 18 \\
\hline
\end{tabular}

\section{Measurement Technique}

For experimental analysis of kerfwidth, straight cuts of 50 $\mathrm{mm}$ in length as shown in figure 1 were made on sheet and measured using 3D microscope MITUTOYO/QS-L2010ZB and its software. Five readings were taken throughout the length of $50 \mathrm{~mm}$ and then average is taken for each cut. Figure 2 shows the sample reading for measurement of kerfwidth.

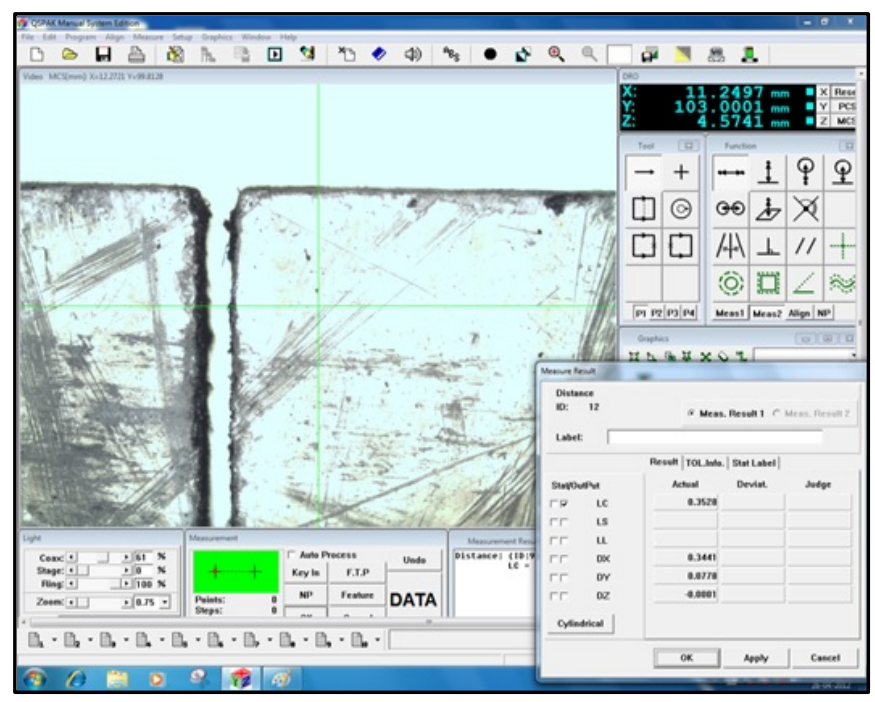

Figure 2: Measurement of Kerfwidth Using 3D Microscope 


\section{VARIOUS Modelling Techniques}

\section{A. ANOVA of Kerfwidth}

MINITAB 16 software is used for performing DOE, ANOVA, and Regression Analysis. Figure 3 shows the main effect plot for kerfwidth. The results of ANOVA for kerfwidth is shown in table 2. It shows that the p-value of laser power and gas pressure are less than 0.05 and hence it is found that the effect of laser power and gas pressure on kerfwidth is significant.

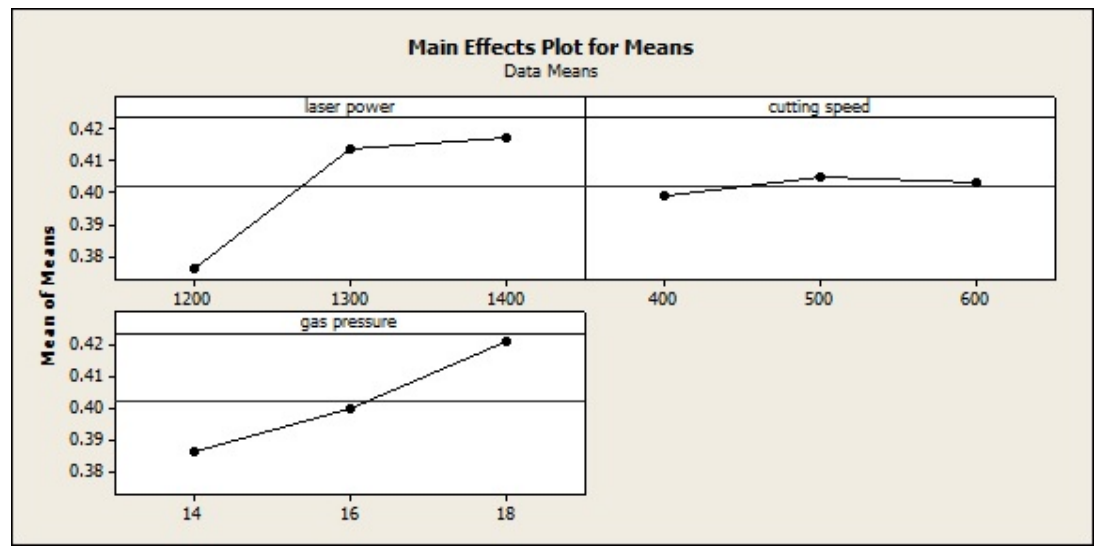

Figure 3: Main Effects Plot for Means for Kerfwidth

Table 2: Results of ANOVA for Kerfwidth

\begin{tabular}{|l|l|l|l|l|l|l|l|}
\hline Source & DF & Seq SS & Adj SS & Adj MS & F & P & \% Contribution \\
\hline Laser power & 2 & 0.0096251 & 0.0096251 & 0.0048126 & 29.1 & 0.000 & 51.72 \\
\hline Cutting speed & 2 & 0.0001650 & 0.0001650 & 0.0000825 & 0.50 & 0.615 & 0.88 \\
\hline Gas pressure & 2 & 0.0055099 & 0.0055099 & 0.0027550 & 16.66 & 0.000 & 29.61 \\
\hline Error & 20 & 0.0033077 & 0.0033077 & 0.0001654 & & & 17.77 \\
\hline Total & 26 & 0.0186078 & & & & & \\
\hline S = 0.0128603 & R-Sq $=82.22 \%$ R-Sq (adj) $=76.89 \%$ \\
\hline
\end{tabular}

\section{B. Regression Model}

Mathematical model has been prepared for kerfwidth using second order regression to investigate and to model the relationship between the response and the predictors from the experimental response value obtained through Taguchi Design. The model developed is shown by equation 1 .

$$
\begin{gathered}
\mathrm{KW}=-2.77536+0.00479361(\mathrm{P})-0.0167736(\mathrm{p})- \\
0.00000173611\left(\mathrm{P}^{2}\right)-0.00000445833\left(\mathrm{P}^{*} \mathrm{p}\right)+ \\
0.000976389\left(\mathrm{p}^{2}\right)
\end{gathered}
$$

\section{Development of Artificial Neural Network Model}

Artificial Neural Network (ANN) is a widely used supervised learning algorithm in which there are forward and backward passes. It is constructed using three layers they are known as input layer, hidden layer and output layer. Using back-propagation, the weights and biases, associated with the neurons are adapted to minimize the mapping error. After repeated presentation of the training data patterns to the model, the weights and biases of the architecture become stabilized and the ANN is said to be trained. The classification or prediction of new data patterns is accomplished by propagating the new pattern through the neural network. The aim of this network is to train the network to achieve a balance between the ability to respond correctly to the input patterns that are used for training and the ability to provide good responses to the new inputs within a specified range [20]. In this present study three input variables viz. laser power, cutting speed and gas pressure and one output variable i.e. kerfwidth are used to established a relation between input and output variables by ANN model. MATLAB 12 application tool is used to develop the ANN model. Figure 4 indicates the architecture used between input and output parameter.

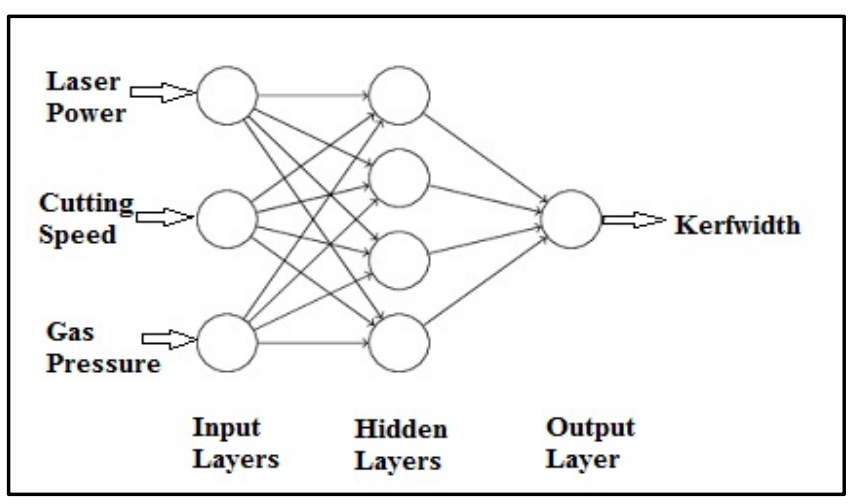

Figure 4: Artificial Neural Network

\section{Development of Fuzzy Logic based Model to Predict Kerfwidth}

Fuzzy Logic (FL) is a common element of Expert System with an increasing rate of interest and widely used over the past few years due to its successful applications in many control and prediction systems. It suits very well in defining the relationship between inputs and desired outputs of a system, where its extra ordinary controlling and reasoning capability made its way to the application of many complex industrial systems. Fuzzy system consists few inputs, output(s), set of predefined rules and a defuzzification method with respect to the selected fuzzy inference system. [15], [16]. 


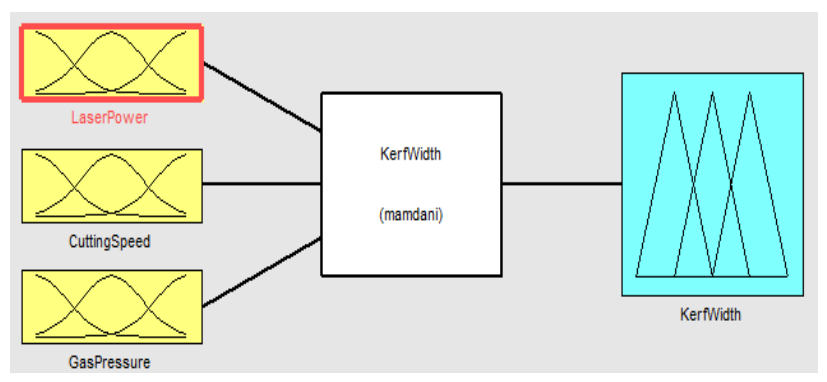

Figure 5: Fuzzy Logic System

MATLAB 12 Fuzzy Logic Tool Box is used to develop Fuzzy Model. Figure 5 shows the structure of fuzzy system in which there are three input variables viz. Laser Power, Cutting Speed and Gas Pressure and one response i.e. kerfwidth. Fuzzy modeling basically involves three main processes viz. fuzzification, fuzzy inference and defuzzification. Fuzzification is the process by which the different linguistic

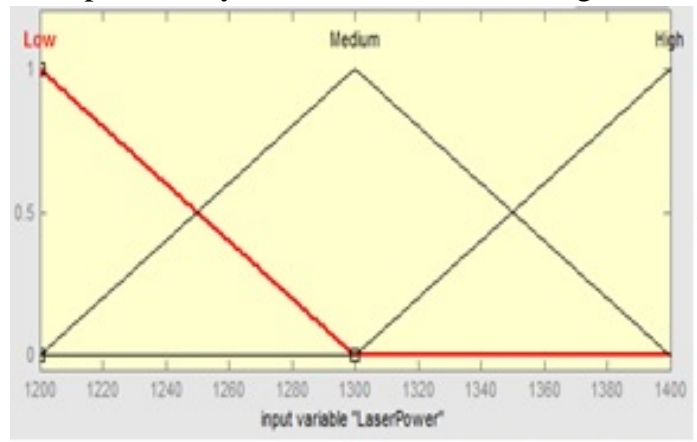

variables are fuzzified by assigning different memberships through the different fuzzy set operations and fuzzy principles. In this process the linguistic variables are converted into fuzzy variables. After the fuzzification process, fuzzy rule base is formed. Finally, the defuzzyfication converts fuzzy predicted value into a real-time value. [18]

\section{i. Membership Functions for Inputs and Output Fuzzy Variables}

In choosing the membership functions for fuzzyfication, the event and type of membership functions are mainly dependent upon the relevant event. Triangular shape of membership function is employed to describe the fuzzy sets for input and output variables. Triangular membership function is generally used and possesses gradually increasing and decreasing characteristics with only one definite value. Figure 6 shows membership functions for each input variable and figure 7 shows membership functions for response[15], [19].
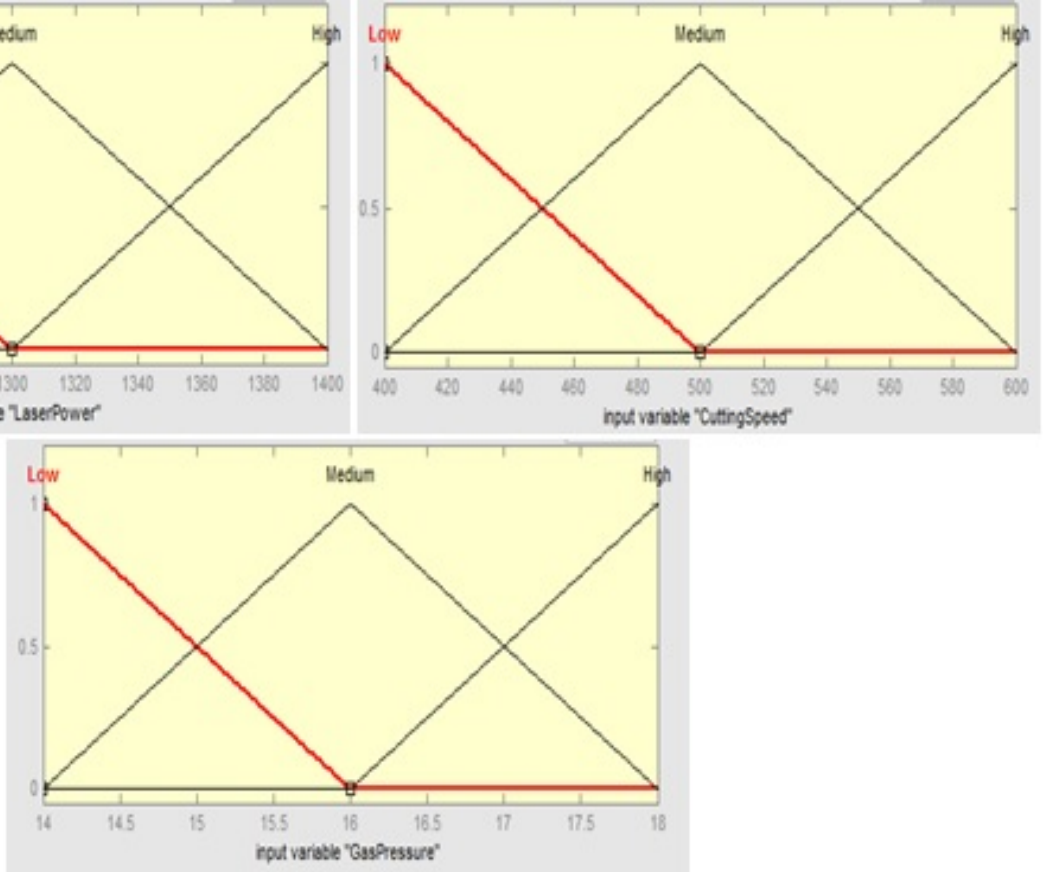

Figure 6: Membership Functions for Laser Power, Cutting Speed and Gas Pressure

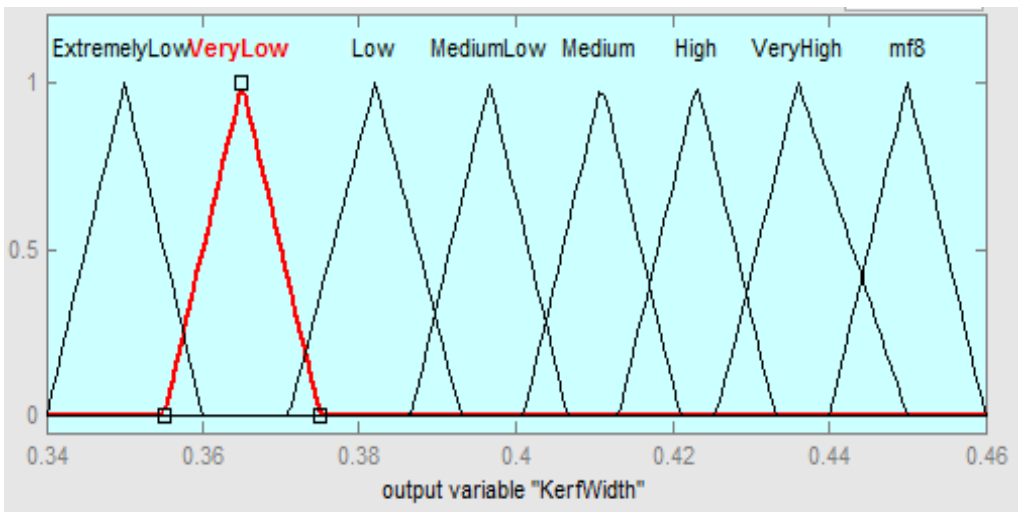

Figure 7: Membership Function for Kerfwidth 


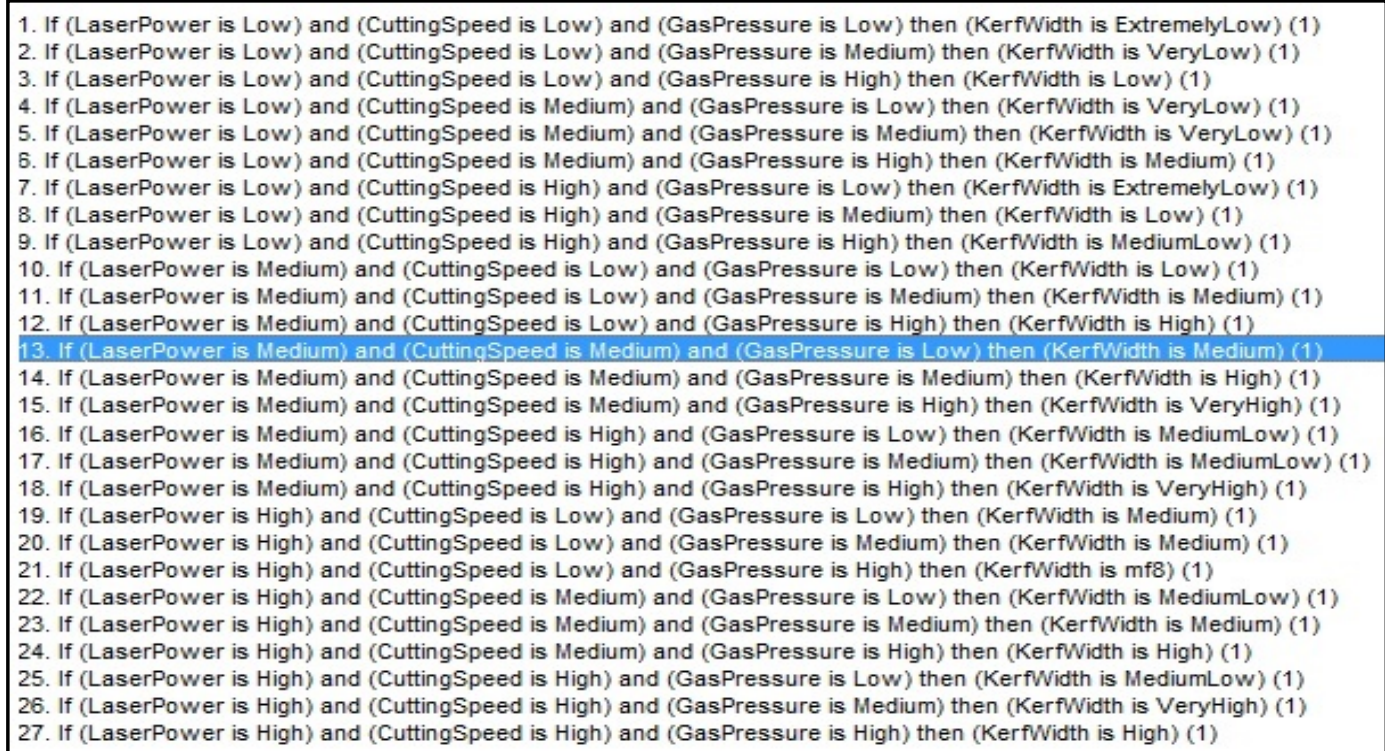

Figure 8: Fuzzy Rules
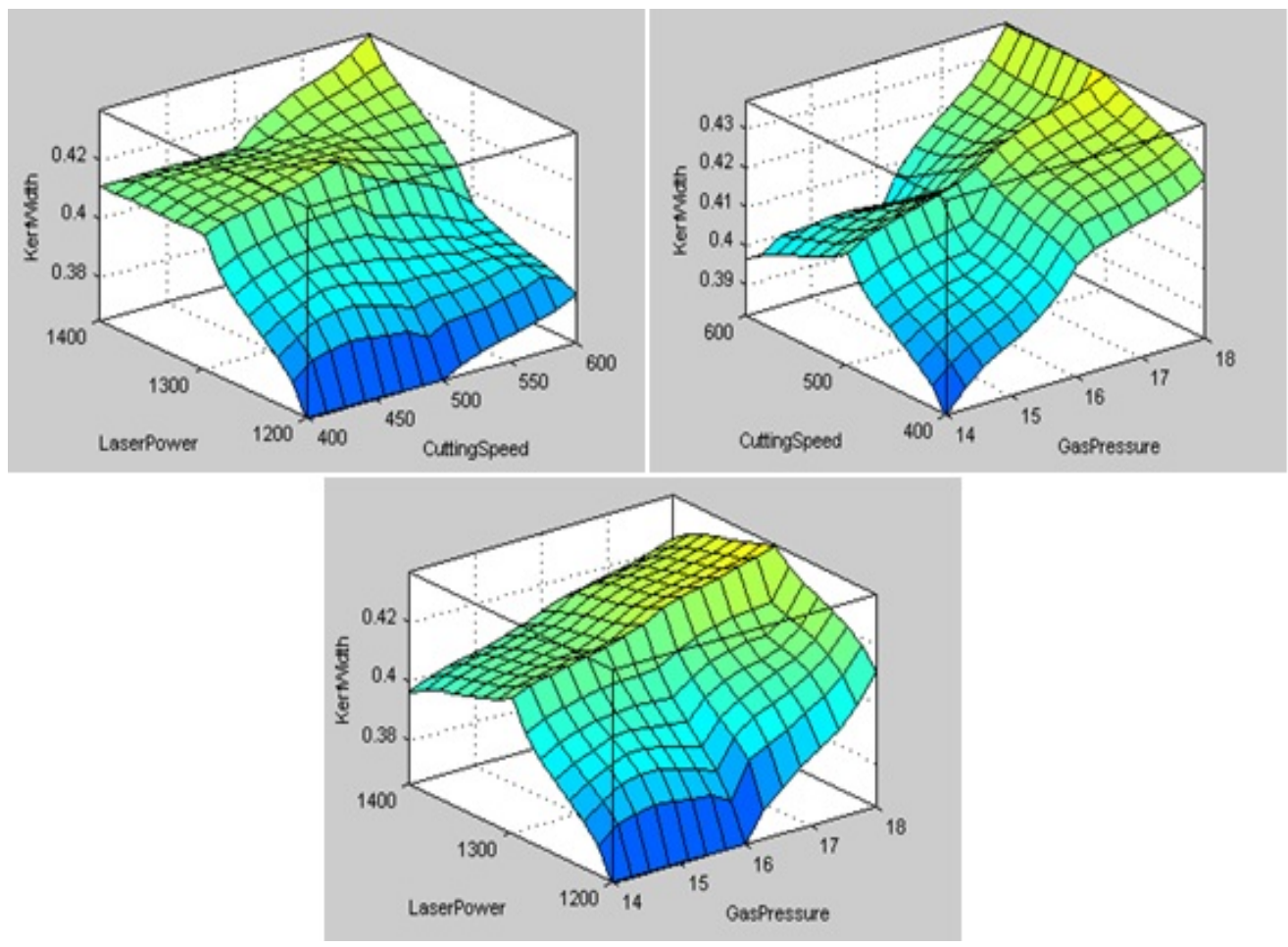

Figure 9: Fuzzy surface plots between Laser power, Cutting Speed, Gas Pressure and Kerfwidth

\section{ii. Fuzzy Rules}

Based on three input variable and their three membership values a set of 27 rules have been constructed based on the actual experimental kerfwidth. Figure 8 shows the set of rules.

\section{iii. Defuzzyfication}

Defuzzyfication is the conversion of the fuzzy quantity to real value. The selection of the method is important as it greatly influences the speed and accuracy of the model. In this model, centroid of area (COA) defuzzyfication method is used due to its wide acceptance and capability in giving more accurate result compared to other methods [15].Figure 9 shows fuzzy surfaces between the Laser Power, Cutting Speed, Gas Pressure and Kerfwidth.

\section{iv. Prediction of kerfwidth using Developed Fuzzy Logic Model}

Figure 10 shows an example of prediction of kerfwidth using developed model. The values of laser power, cutting speed and gas pressure taken are $1300 \mathrm{~W}, 500 \mathrm{~mm} / \mathrm{min}$ and 16 bar respectively and the predicted value of kerfwidth obtained by model is $0.423 \mathrm{~mm}$. 


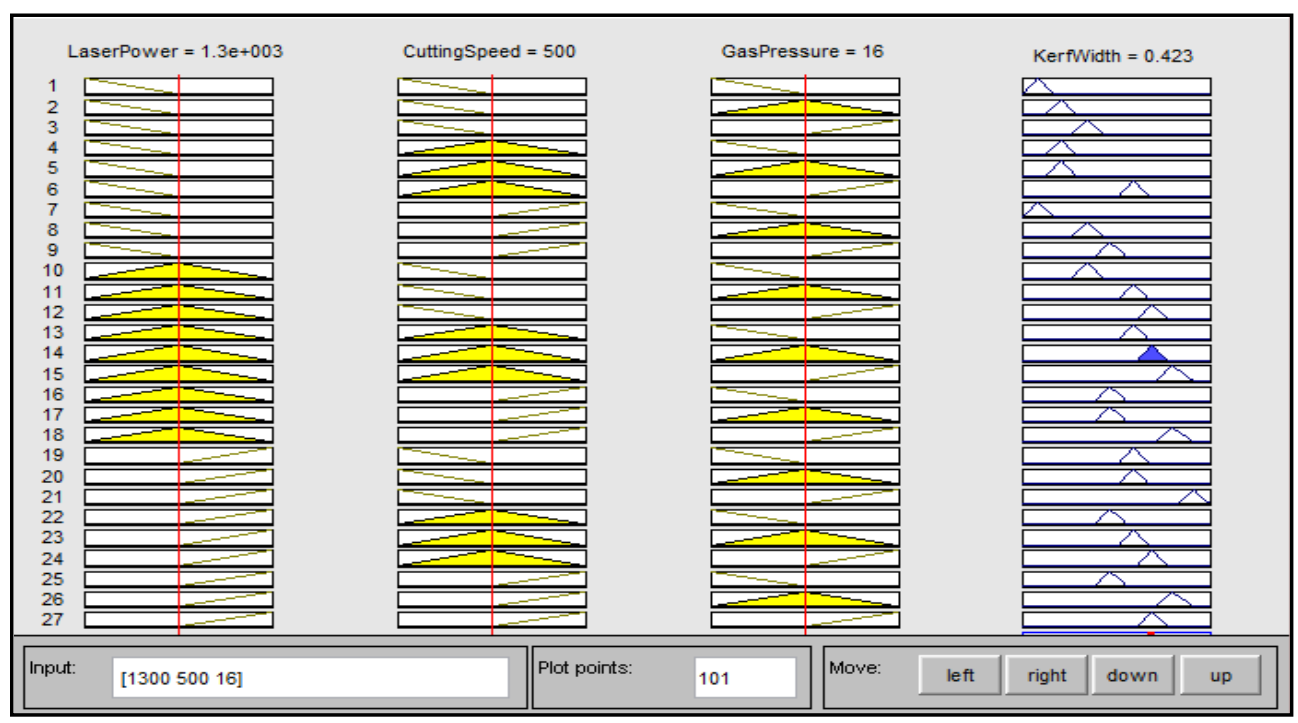

Figure 10: Predicted Value of Kerfwidth Using Fuzzy Mode

Table 3: Values of Kerfwidth

\begin{tabular}{|c|c|c|c|c|c|c|c|}
\hline $\begin{array}{l}\text { Experiment } \\
\text { Number }\end{array}$ & $\begin{array}{l}\text { Laser } \\
\text { Power }\end{array}$ & $\begin{array}{l}\text { Cutting } \\
\text { Speed }\end{array}$ & $\begin{array}{c}\text { Gas } \\
\text { Pressure }\end{array}$ & $\begin{array}{l}\text { Experimental } \\
\text { Kerfwidth }\end{array}$ & $\begin{array}{l}\text { Regression } \\
\text { Kerfwidth }\end{array}$ & $\begin{array}{c}\text { ANN } \\
\text { Kerfwidth }\end{array}$ & $\begin{array}{c}\text { Fuzzy } \\
\text { Kerfwidth }\end{array}$ \\
\hline 1 & 1200 & 400 & 14 & 0.3486 & 0.3198 & 0.3522 & 0.35 \\
\hline 2 & 1200 & 400 & 16 & 0.3663 & 0.3983 & 0.3664 & 0.365 \\
\hline 3 & 1200 & 400 & 18 & 0.3819 & 0.3717 & 0.3818 & 0.382 \\
\hline 4 & 1200 & 500 & 14 & 0.3699 & 0.3885 & 0.3697 & 0.365 \\
\hline 5 & 1200 & 500 & 16 & 0.3601 & 0.3246 & 0.3607 & 0.365 \\
\hline 6 & 1200 & 500 & 18 & 0.4141 & 0.4589 & 0.4144 & 0.411 \\
\hline 7 & 1200 & 600 & 14 & 0.3559 & 0.3964 & 0.355 & 0.35 \\
\hline 8 & 1200 & 600 & 16 & 0.3876 & 0.4042 & 0.3877 & 0.382 \\
\hline 9 & 1200 & 600 & 18 & 0.3956 & 0.4173 & 0.3969 & 0.397 \\
\hline 10 & 1300 & 400 & 14 & 0.3874 & 0.322 & 0.3874 & 0.382 \\
\hline 11 & 1300 & 400 & 16 & 0.4169 & 0.439 & 0.4029 & 0.411 \\
\hline 12 & 1300 & 400 & 18 & 0.4237 & 0.4456 & 0.424 & 0.423 \\
\hline 13 & 1300 & 500 & 14 & 0.4096 & 0.3828 & 0.3973 & 0.411 \\
\hline 14 & 1300 & 500 & 16 & 0.4226 & 0.4659 & 0.409 & 0.423 \\
\hline 15 & 1300 & 500 & 18 & 0.4308 & 0.482 & 0.4306 & 0.437 \\
\hline 16 & 1300 & 600 & 14 & 0.4058 & 0.4199 & 0.4061 & 0.397 \\
\hline 17 & 1300 & 600 & 16 & 0.3901 & 0.3839 & 0.3904 & 0.397 \\
\hline 18 & 1300 & 600 & 18 & 0.4369 & 0.4512 & 0.4358 & 0.437 \\
\hline 19 & 1400 & 400 & 14 & 0.4108 & 0.4325 & 0.411 & 0.411 \\
\hline 20 & 1400 & 400 & 16 & 0.4009 & 0.3988 & 0.401 & 0.411 \\
\hline 21 & 1400 & 400 & 18 & 0.4532 & 0.493 & 0.4345 & 0.45 \\
\hline 22 & 1400 & 500 & 14 & 0.3905 & 0.4135 & 0.3907 & 0.397 \\
\hline 23 & 1400 & 500 & 16 & 0.4202 & 0.4432 & 0.4133 & 0.411 \\
\hline 24 & 1400 & 500 & 18 & 0.4252 & 0.4677 & 0.4255 & 0.423 \\
\hline 25 & 1400 & 600 & 14 & 0.3967 & 0.4176 & 0.3969 & 0.397 \\
\hline 26 & 1400 & 600 & 16 & 0.4315 & 0.4759 & 0.4316 & 0.437 \\
\hline 27 & 1400 & 600 & 18 & 0.4261 & 0.4019 & 0.4213 & 0.423 \\
\hline
\end{tabular}




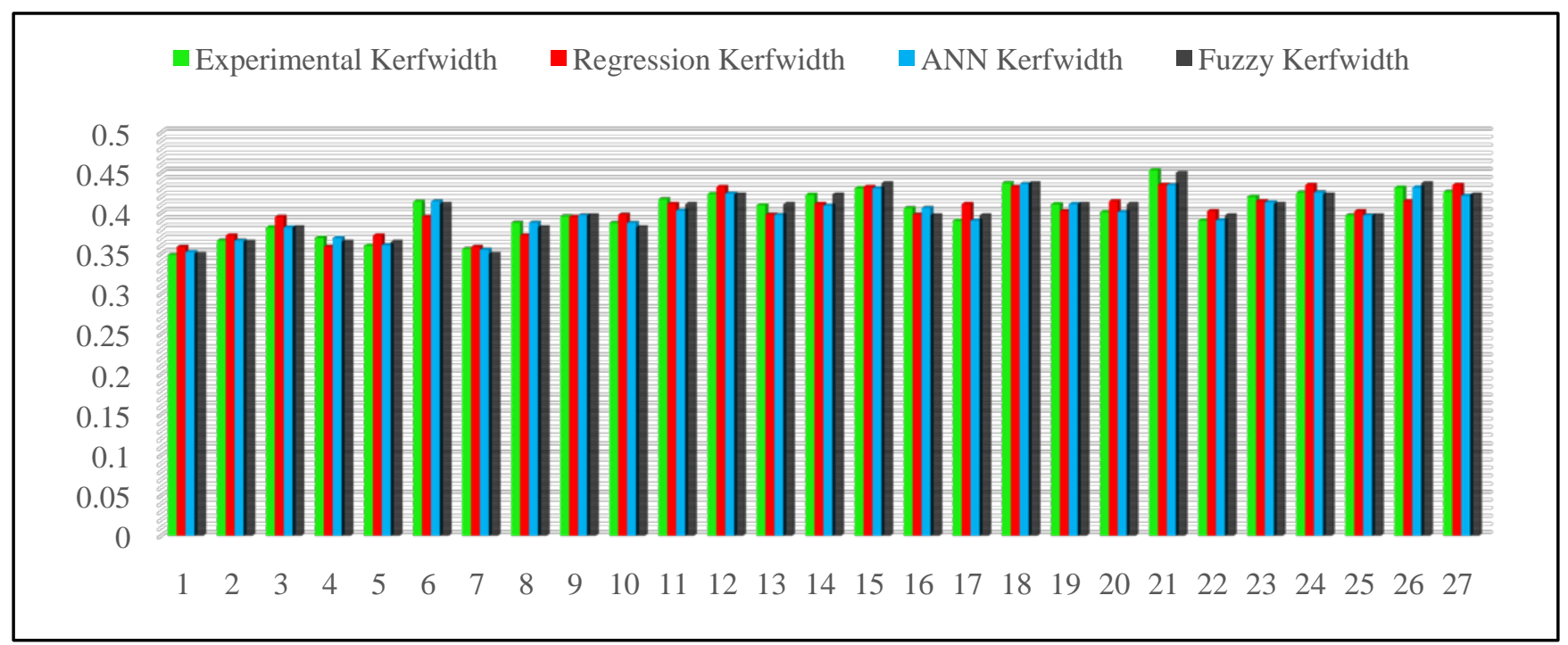

Figure 11: Comparison of Kerfwidth Results

\section{COMPARISON OF VARIOUS MODELING TECHNIQUES}

Table 3 shows the results of experimental kerfwidth and predicted kerfwidth using Regression model, ANN model and Fuzzy Logic model and Figure 5 shows the comparison.

\section{CONCLUSION}

In this present study laser cutting of GFRP has been carried out in order to find the effect of laser cutting parameters on kerfwidth. Second order Regression ANN and Fuzzy Logic based models have been developed from experimental data to predict the kerfwidth. All models and experimental results were compared in terms of the percentage error. It is found that the maximum, minimum and mean percentage errors for regression model are $5.39 \%, 0.12 \%$ and $2.52 \%$ respectively, for ANN model are $4.12 \%, 0 \%$ and $0.71 \%$ and for Fuzzy model are $0.02 \%, 2.51 \%$ and $0.96 \%$ respectively. From these it seems that Fuzzy Logic modelling technique is more accurate in predicting the response. Based on the experimental results, modelling through regression analysis, ANN and Fuzzy Logic, it is found that the kerfwidth increases with increase in the laser power and gas pressure. Thus the developed model is well suited within the specific range of inputs.

\section{ACKNOWLEDGMENT}

The authors would like to express their thanks to Sahajanand Laser Technology Ltd. Gandhinagar, Gujarat and their staff for their invaluable contribution and allowing us to perform the experiments.We are highly thankful to the statistics department, SPU, V. V. Nagar for extending their help in using MINITAB 16.

\section{REFERENCE}

[1] Pathik Patel, Piyush Gohil and Shilpesh Rajpurohit, "Laser Machining of Polymer Matrix Composites: Scope, Limitation and Application”, International Journal of Engineering Trends and Technology (IJETT), Vol. 4, No. 6, Pp. 2391-2399, 2013.

[2] Pathik Patel, Bhavin S. Modi, Saurin Sheth and Tejas Patel, "Experimental Analysis and Prediction of Kerfwidth in Laser Cutting of
Glass Fibre Reinforced Plastic Composite Material”, Proceedings of International Conference on Advances in Materials, Manufacturing and Applications (AMMA 2015), April 9-11, 2015.

[3] E. Fitzer and L.M. Manocha, "Carbon Reinforcements and Carbon/Carbon Composites”, Springer Verlag, 1998.

[4] Chinmaya R. Dandekar and Yung C. Shin, "Modeling of Machining of Composite Materials: A review", International Journal of Machine Tools \& Manufacture, Vol. 57, Pp. 102-121, 2012.

[5] G. Caprino, V. Tagliaferri and L. Covelli, "Cutting Glass Fibre Reinforced Composites using $\mathrm{CO}_{2}$ Laser With Multimodal-Gaussian Distribution”, International Journal of Machine Tools \& Manufacture, Vol. 35, Pp. 831-840, 1995.

[6] Jose Mathew, G.L. Goswami, N. Ramakrishnan, and N.K. Naik, "Parametric Studies on Pulsed Nd:YAG Laser Cutting of Carbon-Fibre Reinforced Plastic Composites", Journal of Materials Processing Technology, Vol. 89-90, Pp. 198-203, 1999.

[7] A.A. Cenna, and P. Mathew, "Analysis and Prediction of Laser Cutting Parameters of Fibre Reinforced Plastics (FRP) Composite Materials", International Journal of Machine Tools \& Manufacture, Vol. 42, Pp. 105-113, 2002.

[8] F.A. Al-Sulaiman, B.S. Yilbas and M. Ahsan, “ $\mathrm{CO}_{2}$ Laser Cutting of A Carbon/Carbon Multilamelled Plain-Weave Structure", Journal of Materials Processing Technology, Vol. 173, Pp. 345-351, 2006.

[9] Avanish Kumar Dubey, and Vinod Yadava,"Multi-Objective Optimization of Laser Beam Cutting Process", Optics \& Laser Technology, Vol. 40, Pp. 562-570, 2008.

[10] S.M. Karazi, A. Issa, D. and Brabazon, "Comparison of ANN and DOE for the Prediction of Laser-Machined Micro-Channel Dimensions", Optics and Lasers in Engineering, Vol. 47, Pp. 956-964, 2009.

[11] Ming-Jong Tsai, Chen-Hao Li and Cheng-Che Chen, "Optimal LaserCutting Parameters for QFN Packages by Utilizing Artificial Neural Networks and Genetic Algorithm”, Journal of Materials Processing Technology, Vol. 208, Pp. 270-283, 2008.

[12] Saurin Sheth, Bhavin S. Modi, Tejas Patel and P M George,"Experimental Investigation and Comparison of Various Modeling Techniques for Prediction of Weld Width in MIG Welding for Dual Plate Check Valve”, 4th Nirma University International Conference on Engineering (NUiCONE 2013), 2013.

[13] Pedram Parandoush and Altab Hossain,"A Review of Modeling and Simulation of Laser Beam Machining”, International Journal of Machine Tools and Manufacture, Vol. 85, Pp. 135-145, 2014.

[14] Tejas Patel, Saurin Sheth, Bhavin S. Modi and Pathik Patel,"Experimental Investigation And Comparison of Regression Model and Artificial Neural Network to Predict Weld Height in MIG Welding for Dual Plate Check Valve", International conference on ADVANCES IN MATERIALS AND PRODUCT DESIGN AMPD 2015, SVNIT, Surat, 2015.

[15] Sheth, Saurin, Bhavin S. Modi, Tejas Patel, and P. M. George. "A Fuzzy Logic Based Model to Predict Weld Width-A Case Study of Hard 
Facing Process Using MIG Welding on Dual Plate Check Valve." Applied Mechanics and Materials, Vol. 592, Pp. 8-12, 2014.

[16] Arindam Majumder, "Comparision of ANN with RSM in Predicting Surface Roughness with respect to Process Parameters in Nd: YAG Laser Drilling”, International Journal of Engineering Science and Technology Vol. 2, Issue 10, Pp. 5175-5186, 2010.

[17] Sivarao, Peter Brevern and N.S.M. El-Tayeb, "A New Approach of Adaptive Network-Based Fuzzy Inference System Modeling in Laser Processing-A Graphical User Interface (GUI) Based”, Journal of Computer Science, Vol. 5, Issue 10, Pp. 704-710, 2009.

[18] Arun Kumar Pandey and Avanish Kumar Dubey, "Intelligent Modeling of Laser Cutting of Thin Sheet”, International Journal of Modeling and Optimization, Vol.1, Issue 2, Pp. 107-112, 2011.

[19] Saurin Sheth, Bhavin S. Modi, P.M. George and Pratik Patel, "A Fuzzy Logic based Model to Predict MRR in Flashing Operation of Precision Steel Ball Manufacturing Process", Procedia Materials Science, Vol. 5,Pp. 1837-1845, 2014.

[20] Bappa Acherjee, Subrata Mondal, Bipan Tudu and Dipten Misra, "Application of Artificial Neural Network for Predicting Weld Quality in Laser Transmission Welding of Thermoplastics", Applied Soft Computing, Vol. 11, Pp. 2548-2555, 2011.

[21] Pratik J. Patel, and Saurin Sheth. "Effect of Various Parameters on Material Removal Rate in Flashing Operation of Precision Steel Ball Manufacturing Process." 1st International and 16th National Conference on Machines and Mechanisms (iNaCoMM2013), Pp. 332-338. 2013.

[22] Pathik Patel and Piyush Gohil, "Laser Machining of Polymer Matrix Composites”, Unpublished M.Tech Thesis, CSPIT, CHARUSAT, 2013. 